\title{
An abdominal-sacral approach with preoperative embolisation for vulvar solitary fibrous tumour: a case report
}

\author{
Akimasa Takahashi ${ }^{1 *}$ (D, Hiroki Nishimura ${ }^{1}$, Tsukuru Amano ${ }^{1}$, Mari Deguchi ${ }^{1}$, Fumi Yoshino ${ }^{1}$, Ryo Kasei ${ }^{1}$, \\ Fuminori Kimura', Suzuko Moritani ${ }^{2}$ and Takashi Murakami ${ }^{1}$
}

\begin{abstract}
Background: Solitary fibrous tumours (SFTs) in the female genital tract are uncommon. Resection of these tumours is controversial because it can cause life-threatening haemorrhage. We report a case of vulvar SFT that was excised in a combined abdominal-sacral approach after preoperative embolisation.

Case presentation: At another hospital, an inoperable intrapelvic tumour was diagnosed in a 34-year-old woman. Computed tomography and magnetic resonance imaging showed that the uterus, urinary bladder and rectum were compressed laterally by a pelvic tumour with a maximum diameter of $11 \mathrm{~cm}$. This mass was hypervascular and had a well-defined border. Transperineal biopsy was performed, and immunostaining revealed that the mass was an SFT. The tumour was supplied by feeding vessels from the right iliac arteries. First, we embolised the feeding vessels. Second, we performed surgical resection in a combined abdominal-sacral approach; no blood transfusion was necessary, and no perioperative complications occurred. The final pathological diagnosis was SFT that was positive for CD34 and signal transducer and activator of transcription 6 according to immunohistochemical staining.
\end{abstract}

Conclusion: During a year of follow-up, the disease did not recur. Treatment of pelvic SFT should aim at complete resection through various approaches after careful measures are taken to prevent haemorrhage.

Keywords: Solitary fibrous tumour, Vulvar, Abdominal-sacral approach, Embolisation, Case report

\section{Background}

Solitary fibrous tumours (SFTs) were first described by Klemperer and Rabin in 1931 as mesenchymal tumours of the pleura [1]. Although SFTs are commonly considered intrathoracic tumours, approximately $30 \%$ of them arise in various extrapleural sites [2, 3]. Of the extrapleural SFTs, those in the female genital tract are rare. This tumour is also characterised by low potential for malignant transformation and by abundant blood vessels. Surgical

* Correspondence: akimasat@belle.shiga-med.ac.jp

${ }^{1}$ Department of Obstetrics and Gynecology, Shiga University of Medical Science, Setatsukinowa-cho, Otsu, Shiga 520-2192, Japan

Full list of author information is available at the end of the article excision with curative intent is generally recommended for the management of this tumour, but controlling bleeding during the operation is often difficult $[4,5]$. Surgical methods are controversial because tumour resection sometimes causes life-threatening haemorrhage.

We succeeded in complete en bloc resection of vulvar SFT, without morbidity or the need for blood transfusion, by a combined abdominal-sacral approach after embolisation of the vessels supplying blood to the tumour.

\section{Case presentation}

A 34-year-old woman was referred to our hospital to evaluate an asymptomatic pelvic mass detected with

C The Author(s). 2021 Open Access This article is licensed under a Creative Commons Attribution 4.0 International License, which permits use, sharing, adaptation, distribution and reproduction in any medium or format, as long as you give appropriate credit to the original author(s) and the source, provide a link to the Creative Commons licence, and indicate if changes were made. The images or other third party material in this article are included in the article's Creative Commons licence, unless indicated otherwise in a credit line to the material. If material is not included in the article's Creative Commons licence and your intended use is not permitted by statutory regulation or exceeds the permitted use, you will need to obtain permission directly from the copyright holder. To view a copy of this licence, visit http://creativecommons.org/licenses/by/4.0/ The Creative Commons Public Domain Dedication waiver (http://creativecommons.org/publicdomain/zero/1.0/) applies to the data made available in this article, unless otherwise stated in a credit line to the data. 
transvaginal ultrasonography in a private clinic, which she had visited for treatment of infertility. Computed tomography $(\mathrm{CT})$ revealed a $112 \times 62 \times 58 \mathrm{~mm}$ hypervascular mass with a well-defined border. This mass compressed the bladder, uterus and rectum in the peritoneum (Fig. 1a). Subsequent contrast medium-enhanced and fat-suppressed T1-weighted magnetic resonance imaging (MRI) then revealed that the tumour had homogeneously high intensity, and T2-weighted images showed a mixture of isointensity in the muscles and high intensity of the tumour, as well as compression of the bladder, uterus and rectum (Fig. 1b, c). Contrastenhanced CT and MRI revealed that the tumour was supplied with blood from the right pudendal artery. Laboratory data revealed no abnormalities such as squamous cell carcinoma antigen, carcinoembryonic antigen, cancer antigen 125, or carbohydrate antigen 19-9. We performed a transperineal biopsy, and the results of which established the diagnosis of SFT.

Before surgery, we performed embolisation of the feeder vessels with an absorbent gelatin sponge to reduce intraoperative blood loss because this SFT was hypervascular, supplied primarily by the right obturator artery and the internal pudendal artery, according to angiography (Fig. 1d). The next day, with the patient in the supine position, we separated the tumour from the right side of the rectum and uterus through a transabdominal approach, which would have been challenging in a narrow and deep pelvis. Laparotomy was performed through a midline incision. We approached the paravesical space and confirmed that the tumour invaded the retroperitoneal cavity. The tumour was well a

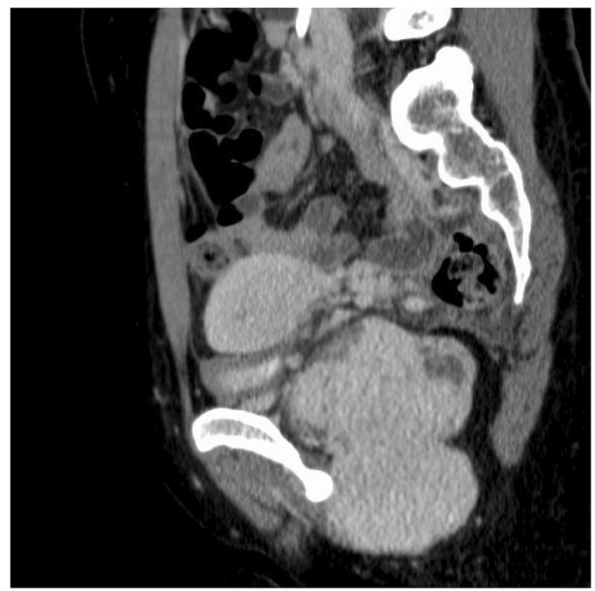

C

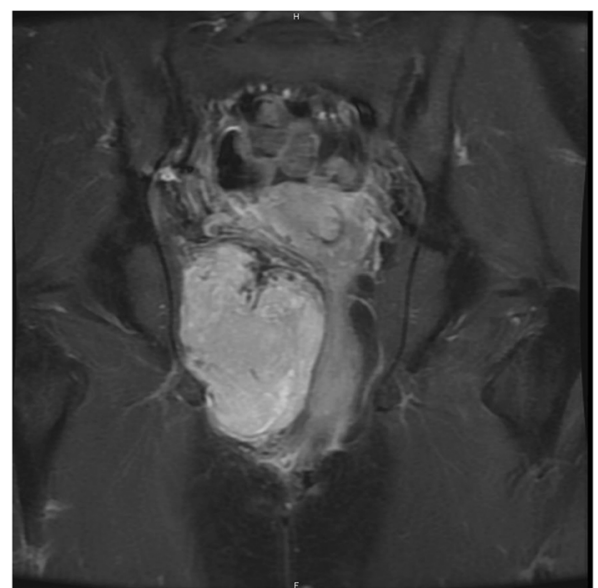

b

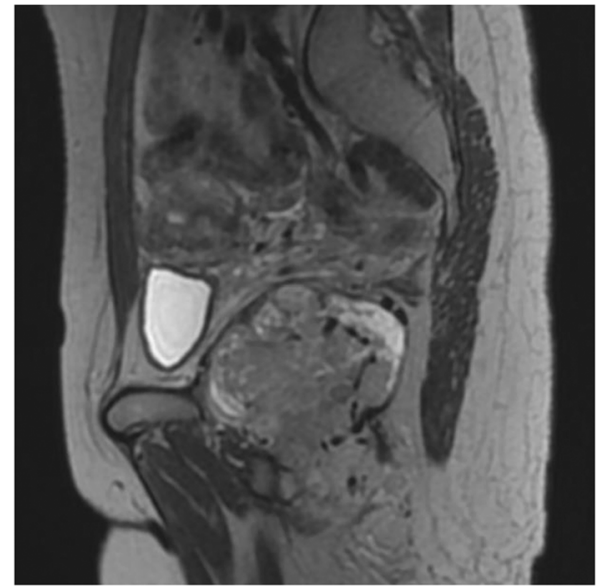

d

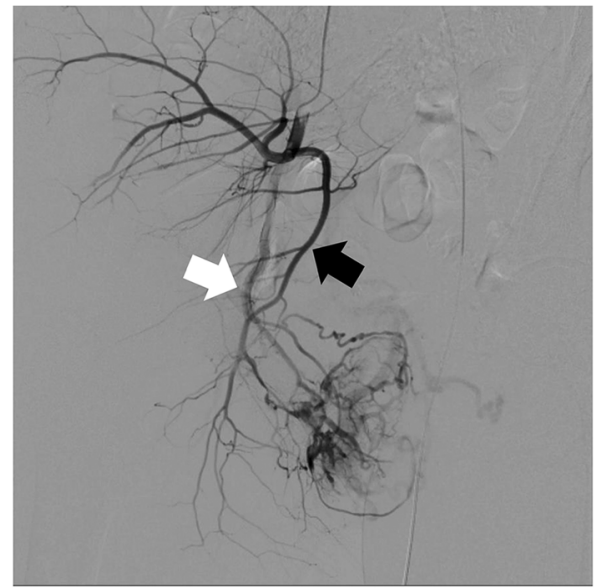

Fig. 1 Preoperative imaging findings. a Preoperative contrast medium-enhanced sagittal computed tomography showed a pelvic mass lesion, measuring $112 \times 62 \times 58 \mathrm{~mm}$. b T2-weighted sagittal magnetic resonance imaging (MRI) showed a mass with heterogeneous intensity in the pelvic cavity. c Fat-suppressed contrast medium-enhanced T1-weighted coronal MRI showed a tumour with a relatively homogeneous contrast effect in the pelvic cavity. $\mathbf{d}$ On angiography of the right iliac artery, the solitary fibrous tumour was found to be supplied by the right obturator artery (black arrow) and the right internal pudendal artery (white arrow) 
encapsulated and had abundant blood vessels around the tumour. We separated as much of the tumour as possible from the levator ani. It could be easily separated from the surrounding muscles. After the wound was closed, the patient was repositioned into the jackknife position for resection through the sacral approach. We made a paramedian skin incision and easily identified the elastic but hard tumour (Fig. 2). We ensured the adequacy of surgical margins to prevent local recurrence and minimise bleeding. That is, the adipose tissue is left to cover the lesion. Finally, the tumour could be removed with en bloc resection. The tumour was completely excised over a period of $223 \mathrm{~min}$ with $250-\mathrm{mL}$ blood loss, and no blood transfusion was required. We did not place the drain anywhere. The postoperative course was uneventful, and she was discharged on postoperative day 7.

Postoperative pathological study showed that the tumour was encapsulated and elastic but hard, and the cut surface was greyish-white (Fig. 3). Microscopic study confirmed that the tumour capsule was not ruptured and was covered with adipose tissue. It was then revealed that the tumour consisted of proliferating, relatively small oval and spindle cells with prominent branching and a hemangiopericytoma-like vascular pattern. Cytological atypia was not significant.
Immunohistochemical staining revealed that the tumour cells were positive for CD34 and for signal transducer and activator of transcription 6 (STAT6) (Fig. 4). The final diagnosis was also SFT. The postoperative course was uneventful; no adjuvant treatment was given because complete surgical resection was achieved. In the year since surgery, the patient has shown no evidence of tumour recurrence.

\section{Discussion and conclusions}

In this case, a solitary fibrous tumour invading the retroperitoneum from the vulva was treated successfully by a combined abdominal-sacral approach after embolisation, without a need of blood transfusion. To our knowledge, this is the first case report of the resection of a vulvar SFT through a combined abdominal-sacral approach.

SFTs are rare soft tissue tumours that commonly arise in the pleura [1]. Such tumours rarely arise from the female genital tract, although they have been reported in various other organs. Nine percent of SFTs occur in the female genital tract, and only 42 cases, including several in the retroperitoneum, have been reported so far $[5,6]$. Furthermore, only 11 cases of vulvar SFTs have been reported [7]. The management of vulvar SFTs is controversial: The prognosis depends on complete resection of both extrapleural and pleural SFTs [5], but surgery is a

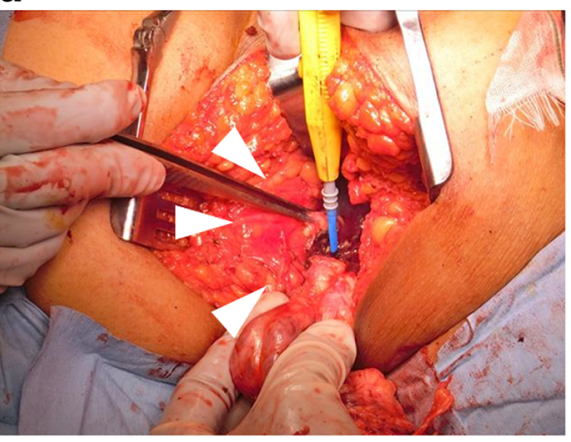

C

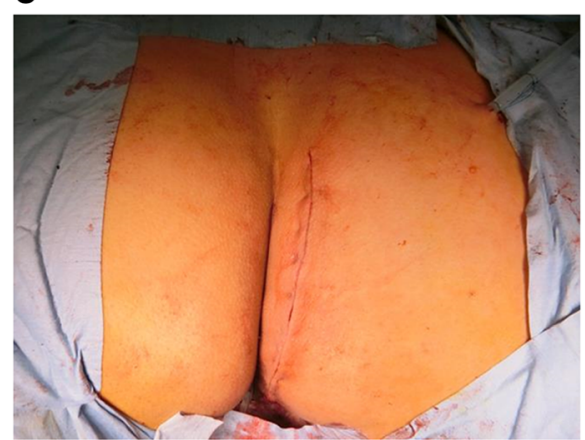

b

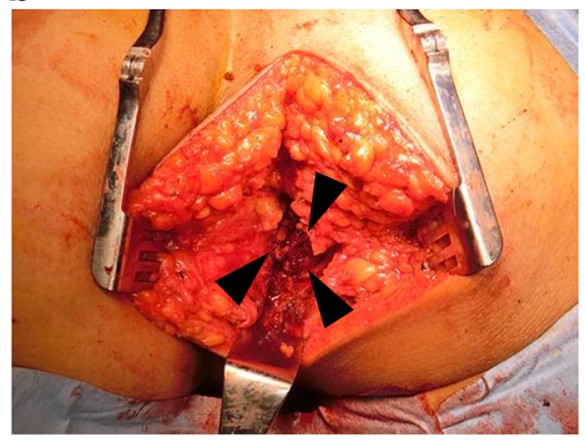

Fig. 2 Intraoperative and postoperative findings of SFT from the sacral view, and postoperative wound. a, $\mathbf{b}$ En bloc resection of the tumour from the pelvic muscle fascia and rectum (white arrow: rectum, block arrow: abdominal cavity) c For tumour resection, the patient was in a jackknife position, and a lateral paramedian incision was made in the skin 


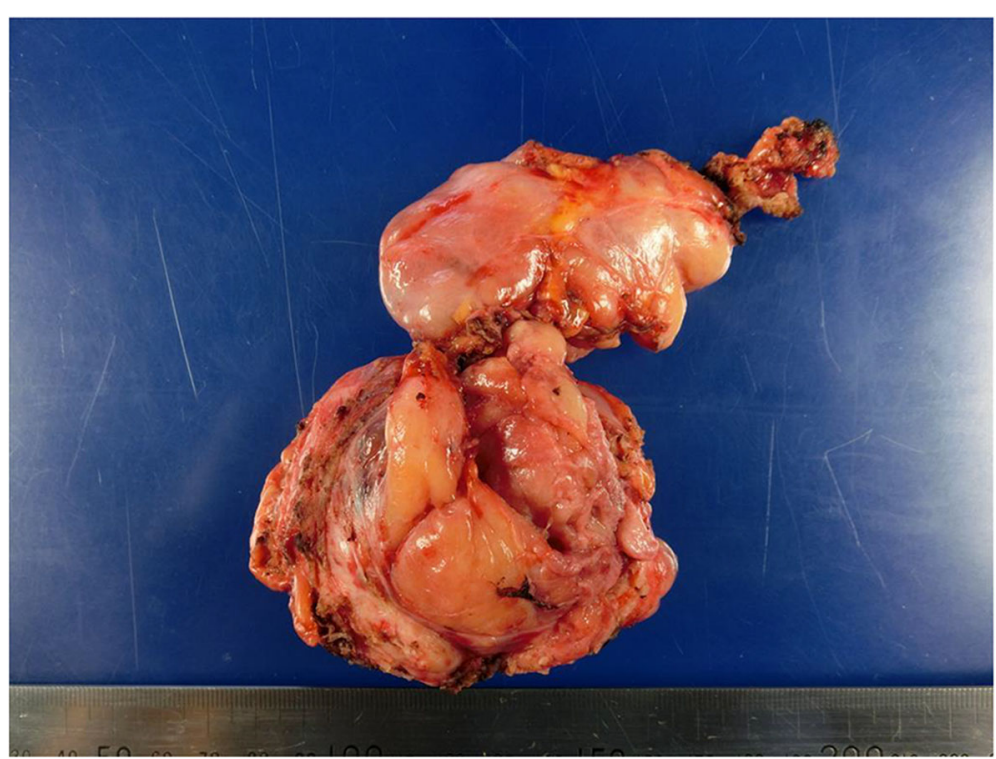

Fig. 3 Gross of solitary fibrous tumour. Photograph of the tumour. Macroscopically, the tumour was elastic but hard, with an intact capsule and the cut surface was greyish-white

a

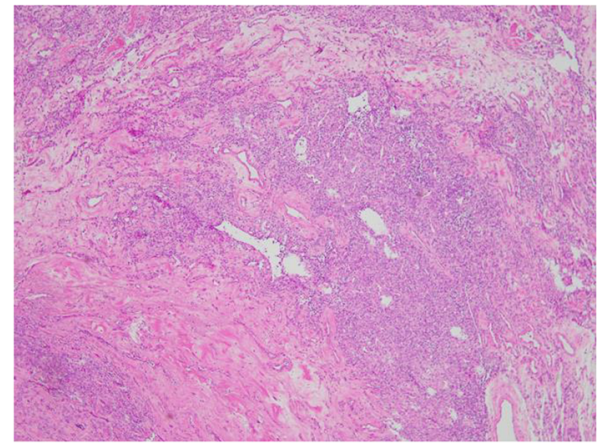

C

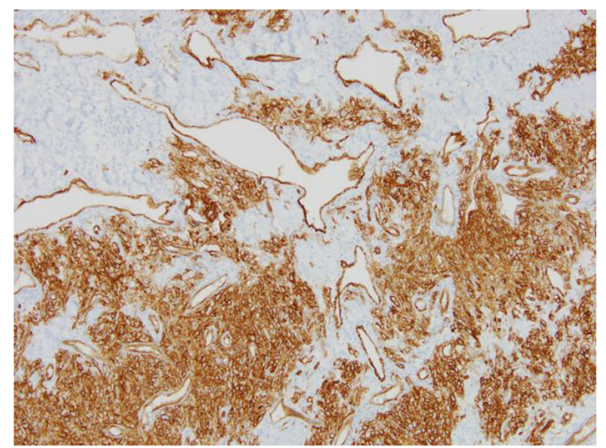

b

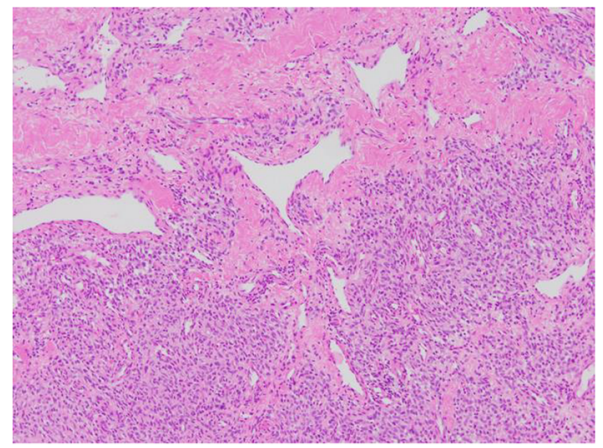

d

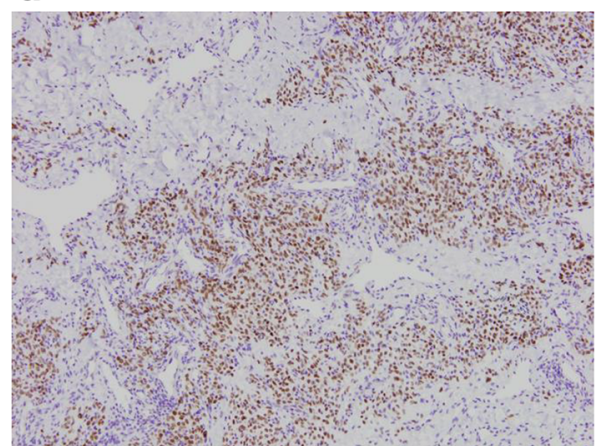

Fig. 4 Microscopic histological findings. a, b Microscopic findings showed spindle cells with a patternless growth arrangement and enlarged blood vessels. (a $\times 40$ magnification, $\mathbf{b} \times 100$ magnification; haematoxylin and eosin stain). $\mathbf{c}$ The tumour cells were strongly positive for CD34 ( $\times 100$ magnification). d The tumour cells were positive for signal transducer and activator of transcription 6. (×100 magnification) 
difficult because of frequent intraoperative heavy bleeding, which occurs because SFTs in the pelvis are usually supplied with blood by multiple vessels, such as the branches of the inferior mesenteric artery or the internal iliac arteries $[8,9]$. Therefore, it is necessary not only to ensure a sufficient blood supply but also to control bleeding during surgery.

SFTs are soft tissue tumours with spindle-shaped cells of mesenchymal origin. From among CD34 immunostaining positive soft tissue tumours, we need to differentiate between SFT and dedifferentiated liposarcoma. Immunohistochemistry for STAT6 protein is useful for diagnosing SFT [10]. Strong expression of STAT6 in the nucleus is an ideal diagnostic indicator for SFT with high sensitivity and specificity [11]. It has been recently reported that STAT6 stains heterogeneously in the nucleus and cytoplasm in spindle-cell de novo dedifferentiated SFT, and the nerve growth factor-inducible protein A binding protein 2 (NAB2)-STAT6 gene fusion was confirmed in this tumour. In our case, the tumour showed the classical morphology of spindle-shaped cells with CD34 staining [12]. Moreover, STAT6 was uniformly and strongly expressed in the nucleus of these cells. Therefore, we diagnosed this tumour as a SFT.

Because the tumour extended from the vulva into the pelvis, we performed the surgery through a combined abdominal-sacral approach out of concern about the difficulty in establishing an appropriate surgical field deep inside the pelvis by laparotomy. For that reason, we first separated the tumour from the right side of the rectum and uterus through a transabdominal approach and then successfully resected the tumour through a transsacral approach. Most patients with pelvic SFTs have undergone laparotomy, but some patients suffer heavy bleeding, which is difficult to control $[9,13]$. In one report, massive bleeding was not avoided even with the transperineal approach [14]. Katsuno et al. reported that the transsacral approach was useful for complete resection of pelvic SFTs [15]; however, this approach carries a high risk of postoperative complications, such as surgical site infection and anal dysfunction [16] (Table 1). In another report, surgery with a combined abdominal-sacral approach was performed for five cases of giant presacral tumours, and complete resection without massive bleeding was achieved. The advantages of this approach are that complications are minimised and it allows for complete resection of a tumour that may be difficult to remove through other approaches [19]. Thus, a combined abdominal-sacral approach can be an option for resecting tumours deep in the pelvis.

We embolised feeder vessels to the tumour before surgery to reduce intraoperative bleeding. Preoperative percutaneous arterial embolisation allows for safe and complete resection in cervical, thoracic and lumbar locations in the spinal cord [20,21]. Embolisation for pelvic SFT has been reported; Soda et al. reported that a tumour was resected after blood flow block was achieved by an intraoperatively inserted aortic balloon catheter, and the resulting blood loss was $13,660 \mathrm{~mL}$ [9]. On the other hand, in other reports, the feeder vessels of SFTs were selectively embolised before operation, which resulted in less intraoperative blood loss without the need for blood transfusion $[14,17,22,23]$. In addition, in two reports, preoperative embolisation did not have the effect of shrinking the tumour $[17,22]$. In our case, we used an absorbable gelatin sponge that has been reported to be pregnant after using it for uterine artery embolisation because she desired for a baby. It is known to be absorbed within 2-6 weeks [18]; therefore, it is reasonable to perform surgery within 2 weeks. Therefore, we performed surgery the day after embolisation. It was possible to complete surgery without blood

Table 1 Summary of surgical outcomes of solitary fibrous tumours in the female pelvis

\begin{tabular}{|c|c|c|c|c|c|c|}
\hline Author & Age & $\begin{array}{l}\text { Tumor size } \\
(\mathrm{cm})\end{array}$ & Way of operation & $\begin{array}{l}\text { Estimated blood } \\
\text { loss }(g)\end{array}$ & Complication & Follow-up (months) \\
\hline Wat, et al. [13] & 63 & $14 \times 11 \times 14$ & Laparotomy & 8,000 & Blood transfusion & N/A \\
\hline Soda, et al. [9] & 27 & $16 \times 9 \times 14$ & Laparotomy & 13,660 & $\begin{array}{l}\text { Blood transfusion, aortic } \\
\text { balloon catheter }\end{array}$ & $\begin{array}{l}\text { Free of disease } 1 \text { year after the } \\
\text { excision }\end{array}$ \\
\hline $\begin{array}{l}\text { Katsuno, et al. } \\
{[15]}\end{array}$ & 56 & $9 \times 7.5 \times 5$ & Trans-sacral approach & 267 & No & $\begin{array}{l}\text { Free of disease } 20 \text { months after } \\
\text { the excision }\end{array}$ \\
\hline Kim, et al. [4] & 52 & $12 \times 9 \times 9$ & Laparotomy & $\begin{array}{l}\text { Massive } \\
\text { hemorrhage }\end{array}$ & Rebleeding $\rightarrow$ reoperation & $\begin{array}{l}\text { Free of disease } 3 \text { years after the } \\
\text { excision }\end{array}$ \\
\hline $\begin{array}{l}\text { Fard-Aghaie, } \\
\text { et al. [17] }\end{array}$ & 70 & $19 \times 14 \times 9$ & $\begin{array}{l}\text { TAE } \rightarrow \text { Abdominoperineal } \\
\text { approach }\end{array}$ & Less than 200 & Permanent colostomy & $\begin{array}{l}\text { Free of disease } 13 \text { months after } \\
\text { the excision }\end{array}$ \\
\hline Yuza, et al. [18] & 46 & 17 & TAE $\rightarrow$ Laparotomy & 335 & lleostomy & $\begin{array}{l}\text { Free of disease } 2 \text { years after the } \\
\text { excision }\end{array}$ \\
\hline Present case & 34 & $11 \times 6 \times 6$ & $\begin{array}{l}\text { TAE } \rightarrow \text { Abdominal-sacral } \\
\text { approach }\end{array}$ & 250 & No & $\begin{array}{l}\text { Free of disease } 6 \text { months after } \\
\text { the excision }\end{array}$ \\
\hline
\end{tabular}


transfusion by performing preoperative embolisation. Therefore, embolisation may control intraoperative bleeding, but it is not effective in reducing tumour volume. In addition, selective embolisation of the feeding vessels is more appropriate than intraoperative aortic occlusion.

In summary, we completely resected a vulvar SFT without blood transfusion. This tumour is very rare, nonmetastatic and characterised by abundant blood vessels. The main treatment for SFTs is surgical resection. However, pelvic SFTs carries the risk of massive bleeding and organ damage, and inadequate tumour resection can lead to local recurrence. Preoperative embolisation of feeder arteries reduced intraoperative bleeding in our patient. In addition, use of the abdominal-sacral approach can reduce perioperative complications. This combination thus has potential in the treatment of pelvic SFTs.

\section{Abbreviations}

CT: Computed tomography; MRI: Magnetic resonance imaging; SFT: Solitary fibrous tumours; CD: Cluste of differentiation; STAT6: Signal transducer and activator of transcription 6

\section{Acknowledgements}

The authors would like to thank Enago (www.enago.jp) for the English language review.

Availability of the data and materials

All the data are available in the patient's medical record.

\section{Authors' contributions}

AT was responsible for this patient's operation, conducted a literature search and drafted with the manuscript. HN, TA, MD, FY, and RK were involved in the gynaecological management of the patient. SM was involved in the pathological diagnosis of the mass. FK and TM contributed to the manuscript review. AT and HN wrote the final version of the manuscript. The authors read and approved the final manuscript.

\section{Funding}

Not applicable.

\section{Declarations}

Ethics approval and consent to participate

This is a case report. The Institutional Review Board at the Shiga University of Medical Science has confirmed that no ethical approval is required. Consent was obtained from the patient for participation in this study.

\section{Consent for publication}

We obtained the patient's consent for publication of this case report.

\section{Competing interests}

The authors have no conflicts of interest relevant to this article.

\section{Author details}

${ }^{1}$ Department of Obstetrics and Gynecology, Shiga University of Medical Science, Setatsukinowa-cho, Otsu, Shiga 520-2192, Japan. Department of Clinical Laboratory Medicine, Shiga University of Medical Science, Kusatsu, Japan.
Received: 9 July 2020 Accepted: 19 March 2021

Published online: 29 March 2021

\section{References}

1. Klemperer P, Rabin CB. Primary neoplasms of the pleura: a report of 5 cases. Arch Pathol. 1931;11:385-412.

2. Gholami S, Cassidy MR, Kirane A, Kuk D, Zanchelli B, Antonescu CR, et al. Size and location are the most important risk factors for malignant behavior in resected solitary fibrous tumors. Ann Surg Oncol. 2017;24(13):3865-71. https://doi.org/10.1245/s10434-017-6092-Z.

3. Wang H, Chen P, Zhao W, Shi L, Gu X, Xu Q. Clinicopathological findings in a case series of abdominopelvic solitary fibrous tumors. Oncol Lett. 2014; 7(4):1067-72. https://doi.org/10.3892/ol.2014.1872

4. Kim MY, Jeon S, Choi SD, Nam KH, Sunwoo JG, Lee JH. A case of solitary fibrous tumor in the pelvis presenting massive hemorrhage during surgery. Obstet Gynecol Sci. 2015;58(1):73-6. https://doi.org/10.5468/ogs.2015.58.1.73.

5. Gold JS, Antonescu CR, Hajdu C, Ferrone CR, Hussain M, Lewis JJ, et al. Clinicopathologic correlates of solitary fibrous tumors. Cancer. 2002;94(4): 1057-68. https://doi.org/10.1002/cncr.10328.

6. Yamada K, Abiko K, Kido A, Minamiguchi S, Horie A, Mandai M. Solitary fibrous tumor arising from pelvic retroperitoneum: a report of two cases and a review of the literature. J Obstet Gynaecol Res. 2019;45(7):1391-7. https://doi.org/10.1111/jog.13965.

7. Chen S, Zheng Y, Chen L, Yi Q. A broad ligament solitary fibrous tumor with Doege-Potter syndrome. Medicine (Baltimore). 2018;97:e12564.

8. Fukunaga M. Atypical solitary fibrous tumor of the vulva. Int J Gynecol Pathol. 2000;19(2):164-8. https://doi.org/10.1097/00004347-20000400000011.

9. Katsuno H, Kainuma O, Yamamoto H, Nagata M, Takiguchi N, Ikeda A, et al. Giant intrapelvic solitary fibrous tumor arising from mesorectum. Clin J Gastroenterol. 2010;3:136-9.

10. Yang EJ, Howitt BE, Fletcher CDM, Nucci MR. Solitary fibrous tumour of the female genital tract: a clinicopathological analysis of 25 cases. Histopathology. 2018;72(5):749-59. https://doi.org/10.1111/his.13430.

11. Yoshida A, Tsuta K, Ohno M, Yoshida M, Narita Y, Kawai A, et al. STAT6 immunohistochemistry is helpful in the diagnosis of solitary fibrous tumors. Am J Surg Pathol. 2014;38(4):552-9. https://doi.org/10.1097/PAS 0000000000000137.

12. Tardío JC, Machado I, Alemany I, López-Soto MV, Nieto MG, Llombart-Bosch A. Solitary fibrous tumor of the vulva: report of 2 cases, including a de novo dedifferentiated solitary fibrous tumor diagnosed after molecular demonstration of NAB2-STAT6 gene fusion. Int J Gynecol Pathol. 2018;37(6): 547-53. https://doi.org/10.1097/PGP.0000000000000464.

13. Wat SY, Sur M, Dhamanaskar K. Solitary fibrous tumor (SFT) of the pelvis. Clin Imaging. 2008;32(2):152-6. https://doi.org/10.1016/j.clinimag.2007.07. 003.

14. Yoshida R, Takada H, Iwamoto S, Uedono Y, Kawanishi H, Yoshioka K, et al A solitary fibrous tumor in the perianal region with a 13-year follow-up: report of a case. Surg Today. 1999;29(7):642-5. https://doi.org/10.1007/BF024 82992.

15. Katsuno H, Maeda K, Hanai T, Sato H, Masumori K, Koide $Y$, et al. Trans-sacral resection of a solitary fibrous tumor in the pelvis: report of a case. Surg Today. 2011;41(11):1548-51. https://doi.org/10.1007/s00595-010-4535-2.

16. Matsushima K, Kayo M. Transsacral approach to resect a gastrointestinal stromal tumor in the rectum: report of two cases. Surg Today. 2007;37(8): 698-701. https://doi.org/10.1007/s00595-006-3466-4.

17. Fard-Aghaie M, Stavrou GA, Honarpisheh $\mathrm{H}$, Niehaus $\mathrm{KJ}$, Oldhafer KJ. Large hemangiopericytoma of the pelvis--towards a multidisciplinary approach. World J Surg Oncol. 2015;13(1):261. https://doi.org/10.1186/s12957-0150675-6.

18. Yuza K, Sakata J, Nagaro H, Ando T, Hirose Y, Miura K, et al. A giant pelvic solitary fibrous tumor with Doege-Potter syndrome successfully treated with transcatheter arterial embolization followed by surgical resection: a case report. Surg Case Rep. 2020;6(1):299. https://doi.org/10.1186/s40792-020-01 076-5.

19. Li GD, Chen K, Fu D, Ma XJ, Sun MX, Sun W, et al. Surgical strategy for presacral tumors: analysis of 33 cases. Chin Med J (Engl). 2011;124:4086-91.

20. Santillan A, Zink W, Lavi E, Boockvar J, Gobin YP, Patsalides A. Endovascular embolization of cervical hemangiopericytoma with Onyx-18: case report and review of the literature. J Neurointerv Surg. 2011;3(3):304-7. https://doi. org/10.1136/jnis.2010.003756. 
21. Aydemir B, Celik S, Okay T, Doğusoy I. Intrathoracic giant solitary fibrous tumor. Am J Case Rep. 2013;14:91-3. https://doi.org/10.12659/AJCR.883867.

22. Yokoyama Y, Hata K, Kanazawa T, Yamaguchi H, Ishihara S, Sunami E, et al. Giant solitary fibrous tumor of the pelvis successfully treated with preoperative embolization and surgical resection: a case report. World J Surg Oncol. 2015;13(1):164. https://doi.org/10.1186/s12957-015-0578-6.

23. Blaine G. Absorbable gelatin sponge in experimental surgery. Lancet. 1951;2: 427-79.

\section{Publisher's Note}

Springer Nature remains neutral with regard to jurisdictional claims in published maps and institutional affiliations.

Ready to submit your research? Choose BMC and benefit from:

- fast, convenient online submission

- thorough peer review by experienced researchers in your field

- rapid publication on acceptance

- support for research data, including large and complex data types

- gold Open Access which fosters wider collaboration and increased citations

- maximum visibility for your research: over $100 \mathrm{M}$ website views per year

At $B M C$, research is always in progress.

Learn more biomedcentral.com/submissions 